\title{
The Effect of Story Narration Regarding Orientation to Pediatric Unit on the Level of Anxiety among Hospitalized Children in Pune City
}

\author{
Deepika Sagar ${ }^{1}$, Pravina Mahadalker ${ }^{2}$, Bhagyashree Jogdeo ${ }^{3}$ \\ ${ }^{1,2,3}$ BVDU College of Nursing, Pune, India
}

\begin{abstract}
Anxiety in children is very much common as they have the fear of the unknown and they don't understand for what they are being admitted in the hospital. So there are many complimentary therapies which are used to relieve anxiety and so one of them is bibliotherapy or reading books as therapy. Purpose : To assess the effect of story narration regarding orientation to pediatric unit is seen on level of anxiety among hospitalized children in Pune city. Objectives: To assess \& compare the level of anxiety before \& after story narration \& to associate the level of anxiety with selected demographic variables. Method: This study based on pre experimental one group pre test, post test research design.100 samples were selected by non probability purposive sampling technique. Modified Spence children anxiety scale was used. Results: In this study Average anxiety score 69.6 with standard deviation of 17.2 before story narration and average score 37.9 with standard deviation of 8.3 were found after story narration. $T$-value corresponding to this comparison were 14.5 at 99 degree of freedom. Corresponding table valued were 2.05, the null hypothesis was rejected. Average anxiety level before story narration was 69.6 which decreased to 37.9 after the story narration therapy. Conclusion: This study concludes that the story narration therapy was effective in reducing the level of anxiety among hospitalized children.
\end{abstract}

Keywords: effect, bibliotherapy, hospitalized children

\section{Introduction}

Identifying anxiety state and seeking remedy to reduce it, will help to increase the coping abilities of the children. In United States of America, it is estimated that 75 percent of children seek care from their primary physician for stress and anxiety for which there are limited known causes or cures[1][8]. An experimental study was conducted on bibliotherapy for reducing childhood anxiety disorders among children using written materials for parents. Two hundred sixty-seven clinically anxious children ages 6-12 years and their parents were randomly allocated for treatment. The study revealed that in around $15 \%$ more children being free of an anxiety disorder diagnosed after 12 and 24 weeks.[2][9].

\section{Literature Survey}

Anxiety is one of the most common psychological disorders in children worldwide. The prevalence rates range from $4.0 \%$ to $25.0 \%$, with an average rate of $8.0 \%$. These figures could be underestimated since anxiety among a large number of children goes undiagnosed owing to the internalized nature of its symptoms[3][3]. World Health Organization estimates that $10 \%$ of the world's population has some form of mental disability and $1 \%$ suffers from severe incapacitating mental disorders. Community-based surveys conducted during the past two decades in India showed that the total prevalence of anxiety disorders was around $5.8 \%$.Hospitalization has the potential to negatively impact a child's motor, cognitive, emotional and social development. Children are sensitive about bodily changes caused by the disease and its treatment e.g. hair loss and resulting impact on self image and self esteem. Some children can regress in behaviour and become overly dependent on their parents. Educational and social development can suffer as a result of frequent school absences.[4][2].

Everyone, from the youngest child to the oldest adult, experiences anxieties and fears at one time or another. Feeling anxious during hospitalization is a particularly uncomfortable situation mainly to children. Dealing with anxieties can prepare children to handle the unsettling experiences and challenging situations of life is a difficult situation to handle [5][3].

To reduce anxiety in children bibliotherapy is a technique used in current medical profession. The written and the spoken word usually appeal to children, so the use of stories as a biblio therapeutic technique in speaking to children, may have considerable therapeutic value .An effort is made to indicate the relationship between reading books and suitable reading material. Reading books can deal with emotional, as well as developmental needs of individuals [6][3].Book reading therapy is an old concept in library science. The ancient Greeks maintained that literature was psychologically and spiritually important, posting a sign above their library doors describing itself as a "healing place for the soul". Book reading therapy has a long history and it is often defined as "healing through books" Literary sources can assist with the resolution of complex problems. The children's became preoccupied with the books and the engagement seemed to be good for their general sense of wellbeing for a variety of reasons [6][3].

Today, healthcare workers and institutions recognize the wide and varied use of book reading therapies within a range of settings. Book reading can assist children in building confidence and self-esteem. It attempts to normalize a child's world by offering coping skills and reducing their feelings of isolation, reinforcing creativity, and problem solving [7][4]. 


\section{International Journal of Science and Research (IJSR) \\ ISSN (Online): 2319-7064}

Index Copernicus Value (2013): 6.14 | Impact Factor (2015): 6.391

\section{Materials and Methods}

In this study the research approach adopted was Quantitative Research Approach. And design adopted was pre experimental one group pre test post test design. The present study was aimed at determining the effectiveness of story narration on levels of anxiety among hospitalized children between the age group 8-12 years who are first time exposed to hospitalization. The hospital anxiety was assessed by using modified Spence children anxiety scale, which was divided in two parts. The first part covered demographic information including age, sex, education, duration of hours since admission and the reason for hospitalization .Second part covered with 25 items, each item was scored as Never(1), Sometimes (2), Often (3), and Always(4).

A score of 25-50 indicates mild anxiety

A score of 51-75 indicates moderate anxiety

A score of 76-100 indicates severe anxiety.

\section{Results}

The demographic information of samples showed Majority i.e. $59 \%$ of the hospitalized children belongs to age 8-10 years and $41 \%$ of them were of age $11-12$ years. $52 \%$ of the hospitalized children were male and $48 \%$ of them were female. They were in almost equal distribution.

Majority i.e. $25 \%$ of children were in $3^{\text {rd }}$ standard, $21 \%$ of them were in $4^{\text {th }}$ standard, $22 \%$ of them were in $5^{\text {th }}$ standard, $17 \%$ of them were in $6^{\text {th }}$ standard, and children studying in $7^{\text {th }}$ standard, $2^{\text {nd }}$ standard, $8^{\text {th }}$ standard were found in almost equal distribution i.e. $10 \%, 4 \% \& 1 \%$.

Majority i.e. 59\% of children were hospitalized for $0-12$ hours and $41 \%$ of them were hospitalized for 13-24 hours. $29 \%$ of children were admitted with GI system related problems, $23 \%$ of children were admitted with PUO and $9 \%, 8 \%, 7 \%$ and $5 \%$ children were admitted with respiratory, urinary, muscular, ENT system related problems. Less number i.e. $1 \%$ and $2 \%$ children were admitted with cardiac, integumentary and lymphatic system related problems.
Table 1: Level of anxiety among hospitalized children before story narration, $\mathrm{N}=100$

\begin{tabular}{|c|c|c|}
\hline ANXIETY & \multicolumn{2}{|c|}{ PRETEST } \\
\hline & Freq & $\%$ \\
\hline Mild & 11 & $11 \%$ \\
\hline Moderate & 54 & $54 \%$ \\
\hline Severe & 35 & $35 \%$ \\
\hline
\end{tabular}

The above data shows pretest, $54 \%$ of the hospitalized children had moderate anxiety (score $51-75), 35 \%$ of them had severe anxiety (Score 76-100) and 11\% of them had mild anxiety (score 25-50) regarding orientation to pediatric unit.

Table 2: Level of anxiety among hospitalized children after story narration, $\mathrm{N}=100$

\begin{tabular}{|c|c|c|c|c|}
\hline ANXIETY & \multicolumn{2}{|c|}{ Pretest } & \multicolumn{2}{c|}{ Posttest } \\
\hline & Freq & $\%$ & Freq & $\%$ \\
\hline Mild & 11 & $11 \%$ & 95 & $95 \%$ \\
\hline Moderate & 54 & $54 \%$ & 4 & $4 \%$ \\
\hline Severe & 35 & $35 \%$ & 1 & $1 \%$ \\
\hline
\end{tabular}

Above data shows pretest, $54 \%$ of the hospitalized children had moderate anxiety (score 51-75), 35\% of them had severe anxiety (Score 76-100) and $11 \%$ of them had mild anxiety (score 25-50) regarding orientation to pediatric unit. In posttest, $95 \%$ of them had mild anxiety (score 25-50), only $4 \%$ of them had moderate anxiety (score $51-75$ ) and $1 \%$ of them had severe anxiety (score 76-100) regarding orientation to pediatric unit. This indicates that the anxiety of hospitalized children improved remarkably after story narration.

Table 3: Comparison of the level of anxiety among hospitalized children regarding orientation to pediatric unit before and after story narration, $\mathrm{N}=100$

\begin{tabular}{|c|c|c|c|c|c|}
\hline $\begin{array}{c}\text { Experimental } \\
\text { group }\end{array}$ & Mean & SD & t & Df & p-value \\
\hline Pretest & 69.6 & 17.2 & 14.5 & 99 & 0 \\
\hline Post-test & 37.9 & 8.3 & 14 & 0 \\
\hline
\end{tabular}

The above data shows the average anxiety score before story narration was 69.6 with SD of 17.2 and which reduced to 37.9 with SD of 8.3 after story narration. T-value for this comparison was 14.5 with 99 degrees of freedom. Corresponding p-value was 0.000 , which is small (less than $0.05)$, the null hypothesis was rejected. Story narration was found to be significantly effective in decreased the anxiety level of the hospitalized children.

$\mathrm{T}_{\text {cal }}>\mathrm{T}_{\text {table }}$ : we reject $\mathrm{H}_{0}$ 


\section{International Journal of Science and Research (IJSR) \\ ISSN (Online): 2319-7064}

Index Copernicus Value (2013): 6.14 | Impact Factor (2015): 6.391

Table 4: Association between levels of anxiety among hospitalized children with their demographic variables. N=100

\begin{tabular}{|c|c|c|c|c|c|c|}
\hline \multirow{2}{*}{\multicolumn{2}{|c|}{ Demographic variable }} & \multicolumn{3}{|c|}{ Anxiety } & \multirow{2}{*}{ p-value } & \multirow[t]{2}{*}{ Significance } \\
\hline & & \multirow{2}{*}{$\begin{array}{c}\text { Mild } \\
6\end{array}$} & \multirow{2}{*}{$\frac{\text { Moderate }}{24}$} & \multirow{2}{*}{$\begin{array}{c}\text { Severe } \\
11\end{array}$} & & \\
\hline Age & 11-12 years & & & & 0.3 & \\
\hline & $8-10$ years & 5 & 30 & 24 & 41 & Not significant \\
\hline \multirow[t]{2}{*}{ Gender } & Female & 6 & 23 & 19 & 0.5 & \multirow[b]{2}{*}{ Not significant } \\
\hline & Male & 5 & 31 & 16 & 24 & \\
\hline \multirow[t]{7}{*}{ Education } & 2nd std & 0 & 3 & 7 & \multirow{7}{*}{$\begin{array}{l}0.5 \\
23\end{array}$} & \multirow{7}{*}{ Not significant } \\
\hline & 3 rd std & 3 & 12 & 10 & & \\
\hline & 4th std & 1 & 13 & 7 & & \\
\hline & 5th std & 2 & 12 & 8 & & \\
\hline & 6th std & 4 & 10 & 3 & & \\
\hline & 7th std & 1 & 3 & 0 & & \\
\hline & 8 th std & 0 & 1 & 0 & & \\
\hline \multirow{2}{*}{$\begin{array}{c}\text { Duration of } \\
\text { hospitalization }\end{array}$} & $0-12$ hours & 5 & 36 & 18 & \multirow{2}{*}{$\begin{array}{c}0.2 \\
19\end{array}$} & \multirow[b]{2}{*}{ Not significan } \\
\hline & 13-24 hours & 6 & 18 & 17 & & \\
\hline
\end{tabular}

The above data shows all the p-values are large (greater than $0.05)$, none of the demographic variable was found to have significant association with anxiety of the hospitalized children.

\section{Conclusion}

Major findings of the study are as follows

Section I: Findings regarding sample characteristic

- $59 \%$ children were between the age group of 8-10 and $41 \%$ were between 11-12 years in the group.

- $52 \%$ children were males and $48 \%$ were females in the group.

- $25 \%$ children were in $3^{\text {rd }}$ standard, $21 \%$ were in $4^{\text {th }}$ standard , 22\% were in $5^{\text {th }}$ standard $17 \%$ were in $6^{\text {th }}$ standard and $7^{\text {th }}$ standard, $2^{\text {nd }}$ standard and $8^{\text {th }}$ standard were found in almost equal distribution i.e. $10 \%, 4 \% \& 1 \%$.

- 59\% were hospitalized within 0-12 hours and $41 \%$ of them were hospitalized within 13-24 hours.

Section II: Findings related to comparison of data to assess the effectiveness of story narration on levels of anxiety among hospitalized children before intervention.

- 54\% children found with moderate hospital anxiety, 35\% children found with severe anxiety and $11 \%$ were found with mild anxiety.

Section III: Findings related to comparison of data to assess effect of story narration on level of hospital anxiety among hospitalized children after intervention.

The level of anxiety among children was improved after the intervention.

- $95 \%$ children were found within mild level of anxiety, $4 \%$ were found within moderate level of anxiety and $1 \%$ was within severe level of anxiety.

Section IV: Findings related to Comparison of pre \& posttest test effect of story narration on level of anxiety among hospitalized children.

T-values corresponding to this comparison were 14.5 at 99 degrees of freedom. Corresponding table values were 2.05 (less than 0.05), the null hypothesis is rejected. Average anxiety level in experimental group before therapy was 69.6 which decreased to 37.9 after story narration. This indicates that the story narration therapy is significantly effective in decreasing the level of anxiety among children admitted in pediatric unit.

Section V (a): To associate the level of anxiety of hospitalized children with their demographic variables

- To associate the findings related to level of anxiety with selected demographic variables in experimental group we used fisher's exact test and since table values corresponding to demographic variables age, gender, education, duration of

- Hospitalization No. of siblings and type of surgery were large, they were found to have no significant association with anxiety in group among children posted for surgery.

On the basis of the findings of the study the following conclusions can be drawn:-

- Children's level of hospital anxiety was high before giving story narration.

- Children exposed to story narration showed significant reduction in the levels of hospital anxiety as compared to pre test results after the intervention.

- Hence story narration was found to be effective in reducing the level of hospital anxiety among children admitted in pediatric unit.

Therefore it can be concluded from the study that story narration can help in reducing the hospital anxiety in children.

\section{Future Scopes}

\section{Nursing Practice}

It has been emphasized in the definition of health by W H O that health is treated as a whole and not as a fragmented element. Hence, to treat patients a nurse needs to pay attention to all the comprehensive aspects of health. Nurse who accompany the patients for maximum time, than any other health professional need to encourage the use of all the other alternative therapies which have shown a significant effect on the health improvement of an individual.

The findings of the present study provides an evidence to overcome the hospital anxiety among pediatric age group by using the non-pharmacological complimentary therapy i.e. story narration 


\section{International Journal of Science and Research (IJSR) \\ ISSN (Online): 2319-7064}

Index Copernicus Value (2013): 6.14 | Impact Factor (2015): 6.391

Story narration is simple to use and cost effective that can be used effectively and independently by nurses to reduce hospital anxiety in children.

This measure will serve as an excellent form of diversion to children from feeling of loneliness, anxiety and an unfamiliar hospital environment. These measures will enhance the ability of nursing personnel in providing quality care, not only in terms of meeting the physical needs of the children but also the overall mental and social development of the child.

The study can be practiced in pediatric unit as daily basis to help the hospitalized children in decreasing the anxiety and cope with the hospital environment.

The results of this study can be included in orientation programme for clients. And make them aware about the hospital environment to reduce the stress and improve cooperation in health care.

An in-service education programme can be organized to sensitize the nurses about the use of story narration in paediatric setting. Nurses should understand the importance of different non pharmacological measures to reduce levels of hospital anxiety.

\section{Nursing Education}

Education is the key to the development of excellence in nursing practice. Education faces tremendous challenges in keeping with pace with the changes in nursing practice to maintain its high quality. Nurses with high education and up to date knowledge will deliver cost effective and quality care. Nursing education is developing fast in India. We are training nurses to achieve an international standard. To achieve high level of educational standards nursing education needs to be raised to a greater height. This is achieved if all the aspects of health needs are considered as a whole.

The Education curriculum must include alternative treatments and methods in the syllabus, which will expose the students to the book reading therapy and make them aware regarding its importance in reducing anxiety in children and to reduce the prolonged duration of hospital stay to reduce the mortality.

Use of bibliotherapy for the reduction of anxiety should be given maximum weightage in staff evaluation.

Focus should be given on bibliotherapy therapy as a diversional therapy for children admitted in hospital.

\section{Nursing Research}

Every profession is enriched and developed because of research in its particular field of interest. Similarly if the nursing profession has to develop it has to do research extensively in areas which are beneficial to the society and humanity. The health care environment today is dynamic and more demanding. There is a need to promote research based practice and the use of evaluation methods to measure outcome and document the quality and cost effective care as nursing moves towards an independent professional practice mode.

Research has a vital and significant role in nursing. Nurses must take up extensive research in field of use of books to reduce anxiety levels. Emphasis should be laid on the publication of research findings in the journal to disseminate the research based evidence for nurse practitioners .It can be presented in various nursing forums so that more number of nurses become aware of book reading therapy and feel the need to include other measures to reduce anxiety in their patient care and practice.

\section{Nursing Administration}

Our rapidly changing world makes it necessary for us nurses to update our knowledge and skills concerning many aspects of nursing care. We must not only keep abreast of scientific and technical advances in health care, but also device ways for more creative use of our existing knowledge and resources, so that best possible nursing care can be provided to the clients

This study has important implication for nursing administration. The overall nursing responsibility of quality nursing care is on the nurse administrator .The nurse administrator should accept the new trends in health care i.e. administration of story narration to reduce the hospital anxiety. Firstly there is a need to sensitize the administrators about the use of bibliotherapy as an effective nursing intervention so that they feel the need to introduce book reading during routine nursing care. An in-service education can also be organized for the nurse administrators to teach them about the effects of story narration technique. Nurse administrator should also provide a conductive environment and facilities in terms of adequate staffing, materials and time to carry out story narration for the children during treatments.

\section{References}

[1] Lyneham Heidi(2001) Clinic Programme For Anxious Kids(COPA-K) Macquarie University. Available from http://understandinganxiety.org.au/anxiety-inchildren/introduction.

[2] Bonn M. The effects of hospitalisation on children. Avaliable from http://www.pubmed.com.

[3] Michele A Bertni. "A pilot study of effects of guided imagery and bibliotherapy on anxiety". 2001.

[4] Paediatric integrated cancer services .Impacts of hospitalisation on children and adolscents. Avaliable from http://www.pics.org.au.

[5] Bibliotherapy. Avaliable from http://en.wikipedia.org/wiki/bibliotherapy.

[6] Marilyn j Hockenberry, David Wilson. Wong's Essentials of paediatric nursing $.8^{\text {th }}$ edition. Noida: Elsevier publications; 2009.

[7] Bogart. Research on bibliotherapy. Avaliable from http://www.homeofbob.com/literature/development/cari ng/biblio.html.

[8] Edelman M , Ficorclli C.A measure of success students and test anxiety .Avaliable from http://ncbi.nlm.nih.gov/pubmed. 


\section{International Journal of Science and Research (IJSR) \\ ISSN (Online): 2319-7064}

Index Copernicus Value (2013): 6.14 | Impact Factor (2015): 6.391

[9] J K Trivedi, P K Gupta. An overview of Indian research in anxiety disorders.2010Jan; vol.1: S210-S 218.

[10] Rapee R M, Abbot M, Lynerham H J. Bibliotherapy for children with anxiety disorders using written materials.2006 Jun;74(3):436-440.

[11] Jones F A. The role of bibliotherapy in health anxiety.2002oct7; Vol-10:498-504.

[12] Coyne. Children's experiences of hospitalisation.2006 Dec; Vol-4:326-36.

[13] Susan Rowan, James, Jean Weiler Ash will. Nursing Care Of Children. $3^{\text {rd }}$ edition. Philadelphia: Elsevier Publications;2007

\section{Author Profile}

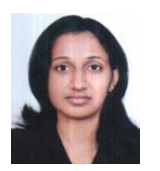

The author name is Deepika Sagar. She is did B.Sc nursing form Choithram College of Nursing, Indore. After completing her bachlore's degree she did MA in English literature from devi ahilya vishvavidhyalaya university. After working for 4 years in JCI accredited international hospital of Jeddah, Saudi Arabia she received her MSC nursing From Bharati Vidhyapeeth Collge Of Nursing Pune .Along with nursing she achieved many awards in academics also.

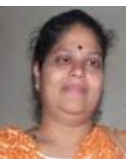

Mrs. Pravina Mahadalker is working as professor in Bharati Vidhyapeeth college of nursing Pune .

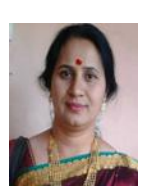

Mrs Bhagyashree Jogdeo is working as assistant professor in Bharati Vidhyapeeth College of nursing Pune. 